\title{
Reference Frames and Astronomy Teaching: The Development of a Topocentric Approach to the Lunar Phases
}

\author{
Diego Galperin*, Andrés Raviolo \\ National University of Rio Negro, Bariloche, Argentina \\ *Corresponding Author: dgalperin@unrn.edu.ar
}

\section{ABSTRACT}

Research related to the teaching and learning of the lunar phases reveals a low level of understanding of this astronomical phenomenon by most students of all educational levels. Therefore, there is a need to develop didactic materials to promote adequate comprehension of this phenomenon and which have been tried out in the classroom. Presented here is the implementation process of a didactic proposal for the teaching of the lunar phases at the primary school level, designed from a topocentric frame of reference. It includes the construction of an explanatory model of the phenomenon, based on observation of the Moon's motion in the sky. Its usefulness lies in that it does not require students to "place themselves in outer space" to describe the lunar movement and in its direct relationship with what they can observe with the naked eye every day. The proposal includes two diagrams that provide alternative images that support the construction of the model. The results obtained indicate that the proposal is effective in improving primary pupils' comprehension of the moon phases.

KEY WORDS: astronomy teaching; lunar phases; topocentric reference frame; primary level

\section{INTRODUCTION}

$\mathbf{N}$ umerous studies carried out over the past 30 years have shown that the lunar phase phenomenon is understood by a very small proportion of students at all educational levels (Baxter, 1989; Sadler, 1992; Schoon, 1992; Bisard et al., 1994; Sharp, 1996; Stahly et al., 1999; Trumper, 2001; Danaia and McKinnon, 2007; Bayraktar, 2009; Álvarez et al., 2018). The reasons behind this may be many, among which are:

i. Difficulties in understanding the phenomenon of lunar phases on the part of teachers, similar to the problems detected in pupils (Camino, 1995; Galperin et al., 2018).

ii. Errors in school textbooks, many of which reinforce the alternative conceptions already held by pupils on the cause of everyday astronomic phenomena (Navarro Pastor, 2009; Galperin and Raviolo, 2017).

iii. Lack of knowledge of research in this area which shows that understanding the lunar phases from the movement of the Moon around the Earth requires considerable visuospatial ability, which is problematic for students of all ages (Callison and Wright, 1993; Suzuki, 2003; Bayraktar, 2009; Dicovskiy et al., 2012).

iv. The prevailing use of the heliocentric system of reference in the great majority of curricular materials, disregarding the possibility of providing an adequate explanation of everyday astronomic phenomena using the topocentric reference system, centered on a given point on the Earth's surface (Galperin and Raviolo, 2014).

Considering this problem, a lunar phases teaching sequence has been designed for primary-level pupils, in accordance with current scientific and didactic knowledge, and has been implemented and evaluated under real classroom conditions. The fundamental core of the plan is to enable pupils to relate to observable aspects of the phenomenon, hence the exclusive use of the topocentric system of reference. As part of the proposal, a visual representation has been prepared which explains the lunar phases in a topocentric way, based on the motion of the Moon in the sky. In this way, it is hoped that pupils can improve their understanding of the phenomenon without having to alternate between two points of view: One from outside the Earth, with the Moon moving in space and always half-lit, and one visible from the Earth's surface, with the Moon moving in the sky and changing its shape from day to day.

The learning achieved using this topocentric proposal does not generate difficulties or alternative conceptions which may later complicate understanding of a heliocentric approach to the lunar phases.

\section{LITERATURE REVIEW}

\section{Conceptions of the Lunar Phases}

Many studies have been carried out with students of different ages to analyze their explanations of the phenomenon of lunar phases. The characteristics of some of these and the conclusions reached are detailed in Table 1.

These results reveal that the lunar phases are understood by a very small proportion of students of all ages. The most common explanation, which appears in most studies, is the "eclipse model," which holds that the lunar phases are due to the shadow cast by the Earth onto the Moon, confusing this phenomenon with what happens during a lunar eclipse. In addition, a considerable proportion of primary school pupils do not manage 


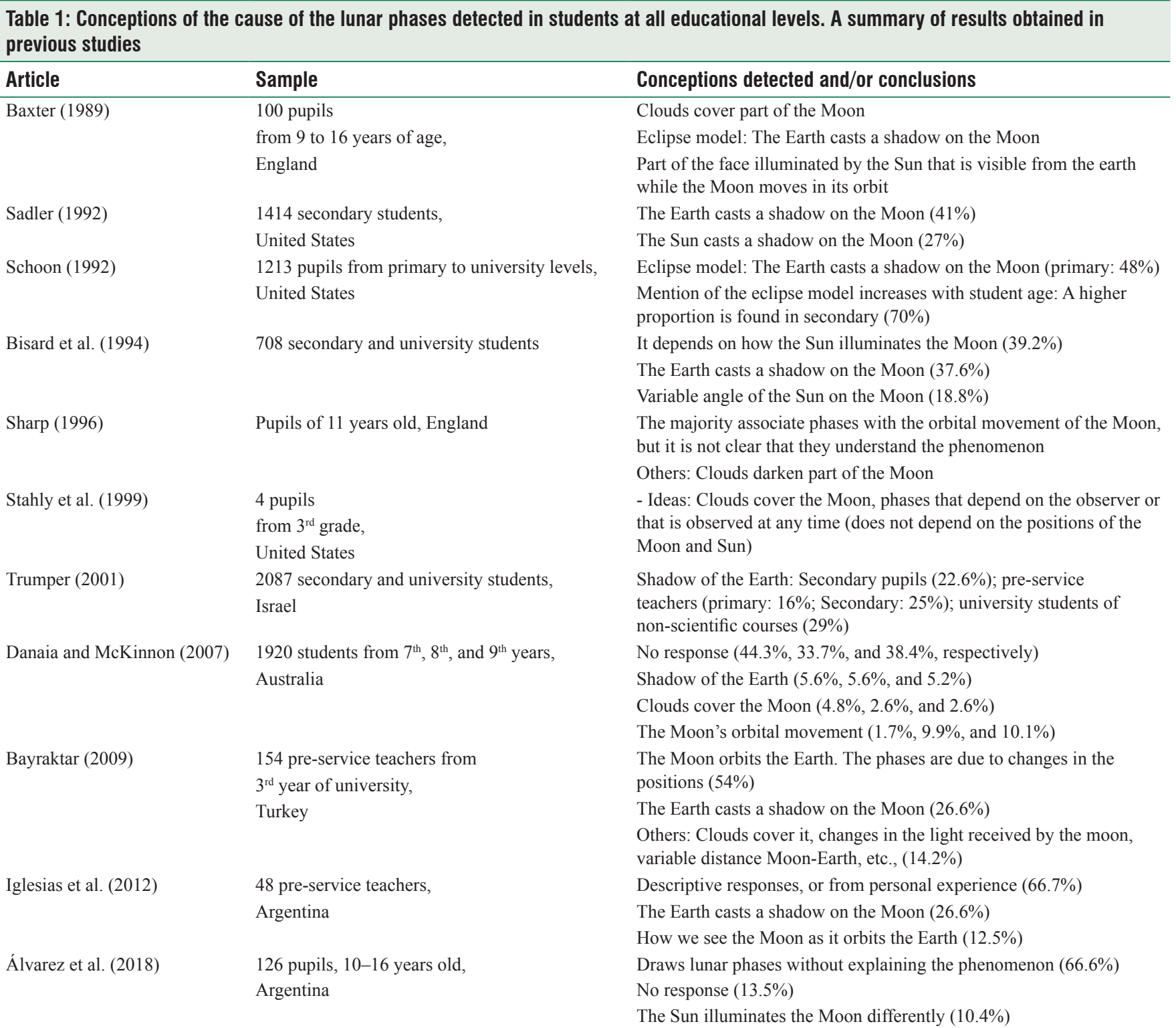

to offer an explanation for the phenomenon, and merely present a description, drawing the different shapes of the moon observed in the sky over a lunar month, although their illustrations are not always consistent with what is actually seen. Figure 1 shows drawings made by students to explain the lunar phases.

Different attempts to explain these difficulties have suggested that they may be related to the only explanation of the phenomenon that appears in most books and audio-visual resources: That it is based on the Moon's movement in space, facing to the Earth a different part of the half illuminated by the Sun. Understanding this explanation of the phenomenon requires visuospatial ability, previous knowledge, and the superimposition of two different points of view, one from outside the Earth, and one from the Earth's surface:

Conceptualizing what causes moon phases requires a highly complex thinking. First of all, students should know the rotating and revolving motions of the moon and the earth and their relative positions to the sun while they move. Second, they should know that the moon is lit by the sun and we can see only the illuminated portion of the moon by the sun. And that this illuminated portion differs in shape as the position of the earth and the moon system changes relative to the Sun. To make a sound understanding of the cause of lunar phases, students should synthesize all these information, and be able to construct a three dimensional image of this trio and their relative motions in their minds (Bayraktar, 2009. p. 12).

Therefore, to explain the lunar phases in this way implies that "you have to change perspective, going to outer space from a point of view on the Earth's surface" (Subramaniam and Padalkar, 2009. p. 18). However, many pupils and teachers do not have the capacity to work from a perspective that is different from that of a terrestrial observer (Suzuki, 2003). At the same time, the construction of a mental model 


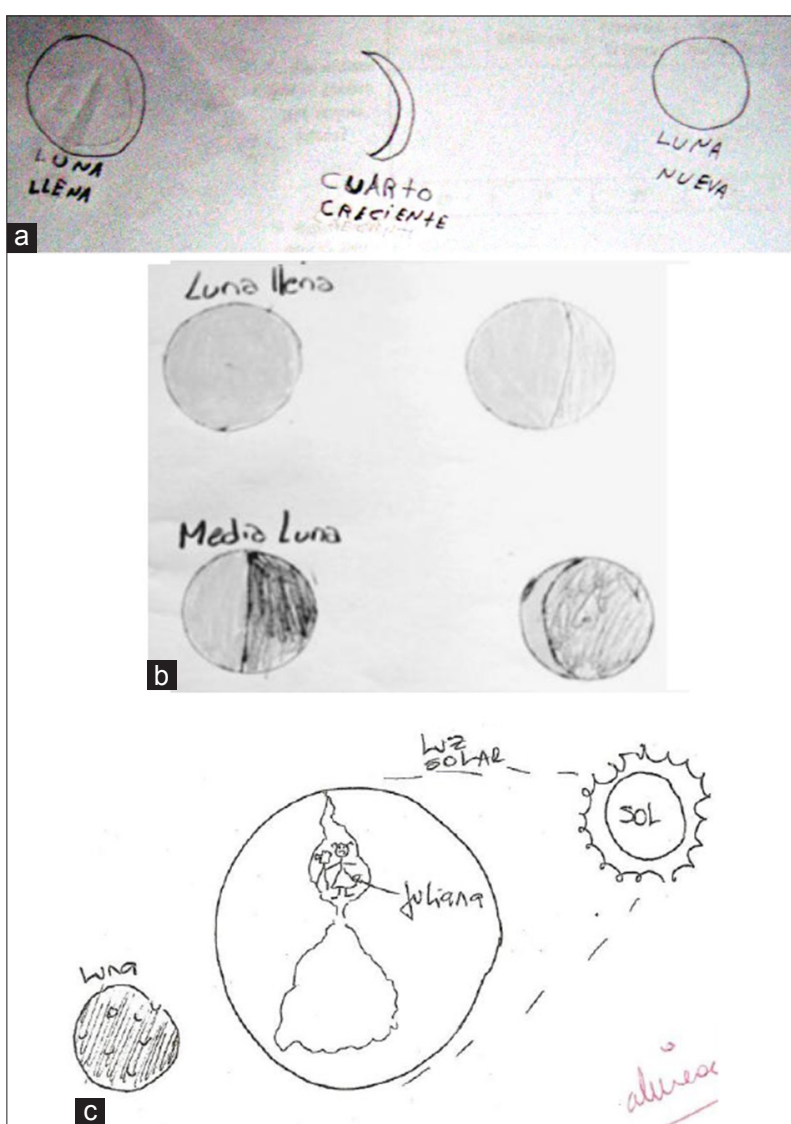

Figure 1: Examples of inadequate explanations of the phenomenon of lunar phases found in investigations carried out in different educational levels. (a) Draws the phases but does not explain the phenomenon (Galperin, 2016). (b) The Sun moves and illuminates the Moon in a different way (Álvarez et al., 2018). (c) The Earth covers the Moon (Iglesias et al., 2012)

able to explain the causes of the phenomenon requires the development of a certain capacity to appreciate the real scale of the system Sun-Earth-Moon (Fanetti, 2001) and a certain level of reasoning and spatial ability (Callison and Wright, 1993) since it requires seeing and working in three dimensions:

Understanding the lunar phases implies a high level of abstraction, as well as a certain ability to work in the three spatial dimensions. It also requires previous knowledge which is fundamental when it comes to resolving situations involved in the SEM system (Dicovskiy et al., 2012. p. 227).

The poor results achieved in terms of comprehension of the lunar phases by students at all educational levels suggests that an alternative method is needed for the teaching of this phenomenon (Aggul Yalcin et al., 2012). Nevertheless, few studies have focused on explaining the phenomenon from a reference frame centered on the Earth's surface which does not require working simultaneously from two different points of view.

In contrast, didactic developments do exist that propose teaching sequences for the lunar phases using the heliocentric reference system, based on the Moon's movement in space, but these do not tend to promote substantial change in students' comprehension of the phenomenon. For example, Palomar (2013) developed a proposal for secondary school students and obtained correct results for only $10.1 \%$ of the students who were instructed. Furthermore, Iglesias et al. (2012), working with pre-service primary teachers, proposed the modeling of the Sun-Earth-Moon system using spheres, which enabled them to experience "the difficulties that arise from the external explanation, since it involves simultaneous consideration of two perspectives: That which is observed from Earth and that observed when one imagines oneself moving a way from it"' (p. 280).

Considering this, we can affirm that there are no justifiable grounds for explaining the phenomenon of the lunar phases to primary school age children, and even adults, exclusively from the perspective outside the Earth. The criteria of simplicity, relationship with the surroundings, and the real possibility of making predictions offer certain advantages to the use of the topocentric reference frame. This does not mean we need to abandon the heliocentric reference frame, but we should use it in the correct context: As a possible way of approaching the explanation of everyday astronomic phenomena, with full knowledge of the associated comprehension difficulties (Galperin, 2016).

\section{Using the Topocentric Reference Frame}

In current textbooks and curricular materials, the subjects of everyday astronomy (day and night, seasons, and lunar phases) are dealt with almost exclusively using the heliocentric reference frame (Galperin and Raviolo, 2014). This would appear to suggest that this is the only possible reference system able to explain these astronomic phenomena, disregarding the possibility of using the topocentric reference frame. However, for a considerable proportion of students, the heliocentric frame is difficult to understand. In addition, although there are certain "advantages" to using this frame to explain certain astronomical phenomena, there are also "disadvantages," since the point of view is completely different to that of an observer on Earth.

In contrast, topocentric descriptions and explanations do not require this change of "perspective" on the part of the observer, since they are centred on a point on the Earth's surface. In this respect, the topocentric explanation of the lunar phases is scientifically satisfactory since the problem is purely kinematic: To understand the phenomenon, it is only necessary to know how the Moon changes its position each day with respect to the Sun.

It should be mentioned that the topocentric reference frame is not associated with the old geocentric model of the universe. On the contrary, the use of updated knowledge of physics enables us to describe the motion of the Moon and the Sun from the point of view of an observer from Earth, placing the origin of the system there (Lanciano, 1989; Camino, 1999; Galperin, 2011).

In sum, given that both reference frames are equally capable of explaining the lunar phases and other celestial phenomena visible from the Earth's surface, the use of either one will depend on the simplicity of the description, the explanation and the predictive capacity in relation to the context (Galperin and Raviolo, 2015). 


\section{Model-based Teaching}

Model-based teaching and learning has received much attention over recent decades (Gilbert and Boulter, 2000). It has been oriented to relate the representations of the world held by scientists on any particular physical phenomenon to those used by teachers in the classrooms, and finally, to the representations of the phenomenon constructed by students. In this context, great differences have been identified between the models of the world used by scientists and those of students, although diverse studies have shown the usefulness of using school science representations as a necessary step toward learning the science of scientists. Thus, school science is not just a simplification of scientists' science, adapted to the level of the pupils, but rather its very own series of linguistic labels, concepts, and models that facilitate students' understanding of the phenomena (Galagovsky and Adúriz-Bravo, 2001).

The concept of a model should, therefore, be worked on in the classroom, so that pupils can understand that all models, whether those used within the school context or those used by scientists, are provisional, perfectible constructions, chosen due to aspects such as simplicity, explanatory power, and theoretical richness (Galagovsky and Adúriz-Bravo, 2001).

Teaching based on models is conceived as any implementation that consists of informative resources, learning activities, and teaching strategies that facilitate the construction of mental models (Johnson-Laird, 1983), with the objective of improving student's comprehension of the models and their role in science. To this end, the construction of teaching models is proposed which, in a similar way to scientific models, can act as mediators between theory and reality (Lombardi, 1998). From this perspective, the long-term learning process consists of following a gradual path from the initial conceptions held by students until reach the target model to be teaching, passing through one or more intermediate models (Clement, 2000).
In accordance with this, the didactic sequence designed for primary level students aims at the reconstruction of a descriptive, explanatory, and predictive topocentric teaching model in relation to the phenomenon of the lunar phases.

\section{TOPOCENTRIC ${ }^{1}$ EXPLANATION OF THE LUNAR PHASES}

The position of the Moon in the sky changes notably if it is observed at the same time of day on 2 consecutive days since it will have moved some $13^{\circ}$ toward the east. This typical motion of the Moon means that each day it changes its angular position with respect to the Sun, and in consequence, its visible shape from the Earth's surface varies considerably. For this reason, even though one half of the Moon is always lit up by the Sun, it is not always possible to see this sector completely, resulting in different situations: The illuminated part may not be visible at all from the Earth (New Moon); a portion of this sector can be seen (waxing or waning Moon) or the entire illuminated sector may be seen (Full Moon).

Figure 2 shows the explanatory topocentric diagram of the waxing lunar phases from when the Moon is positioned near the Sun in the sky (position 1) up to when, after approximately 15 days, it is found in the opposite direction (position 9). Numbers indicate the different positions of the Moon, half-lit, as it moves toward the east (always at the same time of day) and letters show how it would be seen from the position of an observer situated at mid-latitudes of the southern hemisphere.

1 The model enables explanation of the changes in the way the Moon is seen in the sky during a lunar month from mid-latitudes of the southern hemisphere. To simplify the model, the Moon's changes in height and the different positions where it rises and sets are not taken into account.

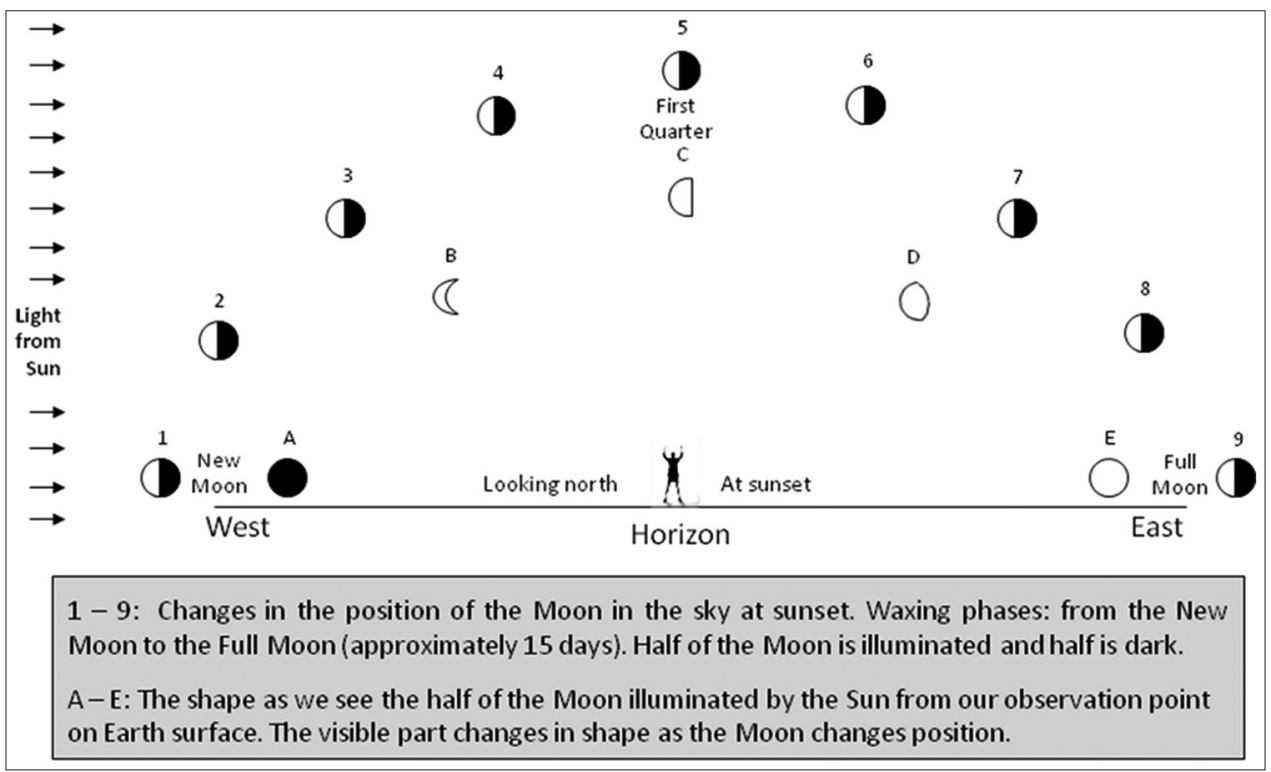

Figure 2: Explanatory topocentric diagram of the waxing Moon phases for an observer looking north from mid-latitudes of the southern hemisphere (Galperin, 2016) 
When the Moon is situated in approximate the direction toward the Sun (position 1), the Moon cannot be seen since its unlighted hemisphere is facing the Earth. In this "New Moon" phase, the Moon rises and sets practically at the same time as the Sun. Over the next days, the Moon's movement toward the east takes it angularly further away from the Sun, and so from the Earth, a larger portion of the illuminated half can be seen each day. Some 7.5 days later, the Moon is positioned in quadrature, at $90^{\circ}$ from the Sun, when exactly half of its illuminated hemisphere is visible (position 5). In this "First quarter" position, the Moon is observed as a semicircle illuminated from the west (the left) due to the presence of the Sun in that direction.

Some 7.5 days later, the Moon is situated at $180^{\circ}$ from the Sun, and so its entire illuminated half is visible (position 9). In this "Full Moon" phase, the Sun and the Moon are opposite each other. Thus, the Moon rises on the eastern horizon approximately when the Sun sets on the western horizon. Since after the Full Moon the Moon's movement toward the east means that it will be below the horizon at sunset, it is necessary to change the time of observation. Consequently, it is convenient to represent the following positions of the Moon at sunrise.

The cycle of lunar phases is divided into two parts. On the one hand, after the New Moon, the "Waxing phases" begins, when the Moon is observed as bigger each day, due to its moving away angular from the Sun until the Full Moon is reached. This "increase" in the size of the Moon in the sky can be seen completely at sunset, registering the position and shape of the Moon over 15 days at the same time of day (Figure 2). In the same way, after the Full Moon the "Waning phases" begins, when the Moon seems to get smaller each day due to its movement toward the east, thus decreasing its angular distance to the Sun. This "decrease" in size of the Moon can be seen completely at sunrise.

Figure 3 shows the explanatory topocentric diagram of the waning lunar phases from when the Moon is opposite to the Sun in the sky (position 9) up to when, after approximately 15 days, it is found in an approximate direction to the Sun (position 17). Numbers indicate the different positions of the Moon at the time of sunrise as it moves toward the east and letters show how it would be seen from the position of an observer situated at mid-latitudes of the southern hemisphere.

After the Full Moon (position 9), the Moon's motion toward the east takes it angularly closer each day to the Sun, and so its illuminated half is gradually less visible from the Earth. Some 7.5 days later, the Moon is positioned again in quadrature with respect to the Sun (position 13) and can be observed as an illuminated semicircle, but now on the eastern side (the right). This is the "Last quarter" phase. Following this, 29.5 days after the beginning of the cycle, the Moon will be close to the Sun in the sky again and will be a New Moon once more, beginning its cycle over again (position 17).

The diagrams show that during the entire waxing phases the Moon is present in the sky at sunset, and observers at midlatitudes of the southern hemisphere will see it with its left side illuminated since the Sun is situated to the west (the left if one is facing north).

In contrast, the waning phases can be seen completely at sunrise, when the Sun is situated to the east (the right if one is looking to the north), so the same observers will see the Moon with its right side illuminated.

In the northern hemisphere, in contrast, these diagrams change because the Moon is observed while facing south and

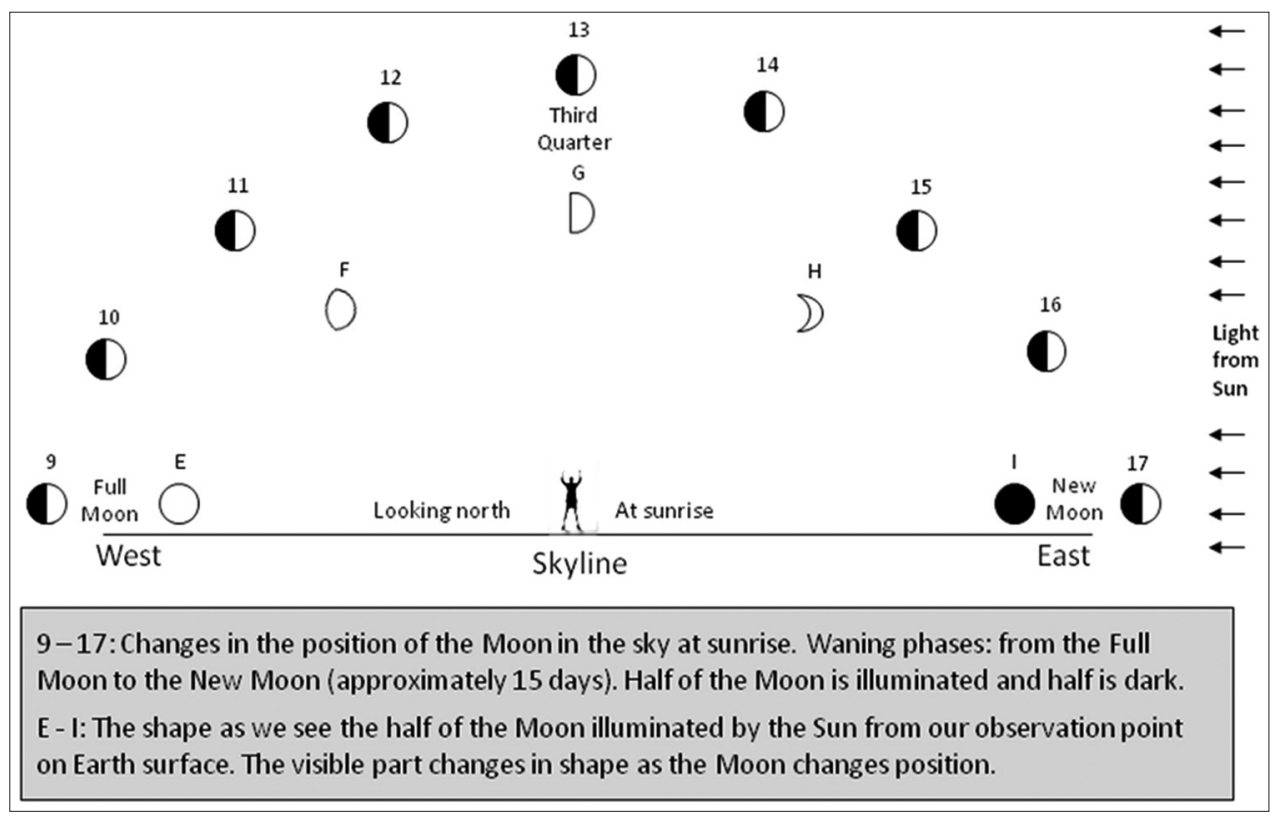

Figure 3: Explanatory topocentric diagram of the waning Moon phases for an observer looking north from mid-latitudes of the southern hemisphere (Galperin, 2016) 
therefore the sides of the Moon which are illuminated are inverted: The right side for the waxing phases and the left side for the waning phases. The explanatory diagrams of the lunar phases corresponding to both hemispheres can be seen here: https://1drv.ms/f/s!AuvrlNHB0HiRi2MszD4vkbkg7T0D.

\section{CHARATERISTICS OF THE TEACHING SEQUENCE}

The purpose of this didactic proposal is for students to modify their initial mental models (largely inconsistent with scientific knowledge) toward a topocentric teaching model that will allow them to understand the phenomenon of lunar phases from the Moon's eastward motion in the sky.

The proposal began by investigating students' conceptions of the cause of the lunar phases (initial questionnaire), which did not differ greatly from those registered in previous studies. Then, descriptions and records of the Moon's motion were made from sky observations with the naked eyes and simulations using "Stellarium" free software (www.stellarium. org). Following this, concrete material was used with which the pupils analyzed how a sphere half illuminated (half painted black and half white) can be observed from different points. This then led into the introduction of explanatory diagrams of the lunar phases from the changes in the position of the Moon in the sky from 1 day to the next (at the same time of day). Finally, the students constructed a model to represent how the phenomenon occurs and then tested their new ideas by responding again to the initial questions and other evaluation questions (Table 2).

\section{METHODOLOGY}

The study was carried out within the framework of qualitative research since we did not aim to corroborate theories or make generalizations; on the contrary, we focused on the search for interpretations and assigning meaning in a particular context (Bryman, 2004). Within this framework, the researcher acted as a class teacher during the implementation of the proposal in the classroom.

The teaching sequence was developed in a $6^{\text {th }}$ grade class of a state primary school situated in a neighborhood close to the center of the city of El Bolsón, Argentina. The activities were carried out in six encounters, each lasting 60 minutes, over a period of three weeks. The class was made up of 26 pupils between 9 and 11 years of age (average 10.6 years), of which 16 were boys and 10 were girls. Most of the pupils are middle class since their parents work in non-professional jobs (47.8\%) or are state employees (39.1\%).

To facilitate analysis of the implementation process, the classes were recorded in audio and video formats. In addition, photographs were taken and all the pupils' work was collected, group and individual, for posterior analysis of each pupil's learning process. The recordings of classroom conversations were transcribed and organized by the encounter, for later evaluation.

To characterize the evolution of pupils' mental models, their work in each class was taken into account, and two semistructured interviews were carried out with some participants, at the beginning and the end of the teaching sequence. This analysis led to the classification of the initial and final mental models used by the pupils to describe and explain the lunar

\section{Table 2: Summary of the sequence carried out and its didactic content}

\begin{tabular}{|c|c|c|c|c|}
\hline No. & Summary & Instruction & Question/s & Topic \\
\hline Act. 1 & $\begin{array}{l}\text { Preliminary inquiry as to pupils' ideas } \\
\text { about the lunar phases and exchange } \\
\text { of ideas }\end{array}$ & $\begin{array}{l}\text { Explain the lunar phases using a } \\
\text { drawing and text }\end{array}$ & $\begin{array}{l}\text { What do you think causes the } \\
\text { lunar phases? }\end{array}$ & Pupils' initial mental models \\
\hline Act. 2 & $\begin{array}{l}\text { Sky observations of the Moon's } \\
\text { eastward motion at sunset and } \\
\text { simulation with Stellarium software }\end{array}$ & $\begin{array}{l}\text { Record how the Moon changes in } \\
\text { position and shape in the form of } \\
\text { a drawing }\end{array}$ & $\begin{array}{l}\text { How does the Moon move in the } \\
\text { sky from one sunset to another? } \\
\text { Does its shape change? }\end{array}$ & $\begin{array}{l}\text { Motion of the Moon toward } \\
\text { the east. Waxing phases }\end{array}$ \\
\hline Act. 3 & $\begin{array}{l}\text { Sky observations of the Moon's } \\
\text { eastward motion at sunrise and } \\
\text { simulation with Stellarium software }\end{array}$ & $\begin{array}{l}\text { Record in the form of a drawing } \\
\text { how the Moon changes in position } \\
\text { and shape }\end{array}$ & $\begin{array}{l}\text { How does the Moon move in the } \\
\text { sky from one sunrise to another? } \\
\text { Does its shape change? }\end{array}$ & $\begin{array}{l}\text { Motion of the Moon toward } \\
\text { the east. Waning phases }\end{array}$ \\
\hline Act. 4 & $\begin{array}{l}\text { Drawing of a half white, half black, } \\
\text { sphere, from different points of view }\end{array}$ & $\begin{array}{l}\text { Place the sphere in a fixed } \\
\text { position. Walk around it and draw } \\
\text { as you see it }\end{array}$ & $\begin{array}{l}\text { Does a half-illuminated object } \\
\text { look the same from different } \\
\text { places? }\end{array}$ & $\begin{array}{l}\text { Half of the Moon illuminated. } \\
\text { Changes in how I see it }\end{array}$ \\
\hline Act. 5 & $\begin{array}{l}\text { Presentation of the explanatory } \\
\text { topocentric diagrams of the lunar } \\
\text { phases }\end{array}$ & $\begin{array}{l}\text { Explanation and group analysis of } \\
\text { the explanatory diagrams }\end{array}$ & $\begin{array}{l}\text { How can the lunar phases be } \\
\text { explained by the Moon's motion } \\
\text { in the sky? }\end{array}$ & $\begin{array}{l}\text { Cause of the phases. Angle } \\
\text { between the Sun and the } \\
\text { Moon }\end{array}$ \\
\hline Act. 6 & $\begin{array}{l}\text { Making of a concrete model to } \\
\text { explain the phases based on the } \\
\text { Moon's eastward motion }\end{array}$ & $\begin{array}{l}\text { Construction of a concrete model } \\
\text { that explains the lunar phases } \\
\text { topocentrically }\end{array}$ & $\begin{array}{l}\text { How does the Moon move in the } \\
\text { sky? Why do the lunar phases } \\
\text { occur? }\end{array}$ & $\begin{array}{l}\text { Moon's motion in the sky. } \\
\text { Phases }\end{array}$ \\
\hline Act. 7 & $\begin{array}{l}\text { Group drawings to explain the lunar } \\
\text { phases topocentrically }\end{array}$ & $\begin{array}{l}\text { Group work: Explanation of the } \\
\text { lunar phases with drawings and } \\
\text { texts }\end{array}$ & Why do lunar phases occur? & $\begin{array}{l}\text { Moon's motion in the sky. } \\
\text { Phases }\end{array}$ \\
\hline Act. 8 & $\begin{array}{l}\text { Analysis of the evolution of pupils' } \\
\text { mental models of the lunar phases }\end{array}$ & $\begin{array}{l}\text { Individual work: Review the } \\
\text { initial inquiry. Answer evaluation } \\
\text { questions }\end{array}$ & $\begin{array}{l}\text { Why do moon phases occur? What } \\
\text { movement are they related to? }\end{array}$ & $\begin{array}{l}\text { Lunar phases. Evolution of } \\
\text { pupils' models }\end{array}$ \\
\hline
\end{tabular}


phases, and in this way establish the effectiveness of the proposal implemented.

\section{FINDINGS}

\section{Characterization of Initial Responses}

From the analysis of Activity 1, carried out by all participants $(n=26)$, it was detected that $38.5 \%$ of the pupils drew the Moon in different shapes but did not manage to give any explanation as to the causes of the lunar phases. Moreover, $15.4 \%$ of the pupils were not able to produce a drawing or an explanation. Finally, $46.2 \%$ of the children drew explanatory diagrams that presented a great diversity of forms, which have been classified into four categories of mental models of the lunar phases $\left(\mathrm{M}_{\mathrm{LP}}\right)$. These categories are described and examples are given in Table 3.

Activity 1 shows the great diversity of explanations given by participants: Three pupils have been included in category $\mathrm{M}_{\mathrm{FL}-1}$, while two were assigned to each of the categories $\mathrm{M}_{\mathrm{LP}-2}, \mathrm{M}_{\mathrm{LP}-3}$, and $M_{L P-4}$. In addition, some responses have not been categorized as they were given by only one pupil: The phases happen "because the Sun is closer or further away from the Moon," "because the world revolves," or "because the Moon changes shape."

Only three pupils, characterized as $\mathrm{M}_{\mathrm{LP}-1}$, were able to offer a satisfactory topocentric explanation of the phenomenon, as they explained the lunar phases from the point of view of how sunlight impacts the Moon so that an observer on the Earth perceives it the way we see it in the sky. They explained that the Full Moon is illuminated by the Sun "from the front," while in the first quarter it should be lit from "the side." However, they seem to associate this with changes in the position of the Sun.

Explanations included in the $\mathrm{M}_{\mathrm{LP}-2}$ category present a heliocentric focus since they imply an imaginary observer "standing" in outer space, observing how the Earth casts a shadow in the opposite direction to the Sun, causing the Moon to be darkened when it moves into this shadow. The use of this model reveals confusion between an eclipse, which is a phenomenon based on shadows, and the phase of a celestial body, which is based on changes in the position of an object, half of which is always illuminated.

The pupils assigned to categories $\mathrm{M}_{\mathrm{LP}-3}$ and $\mathrm{M}_{\mathrm{LP}-4}$ gave explanations of the phenomenon, but in a vague or ambiguous form, and so did not establish a cause-effect relationship between what they mentioned and the changes in phases. In Table 4, the different initial responses given by pupils in relation to the lunar phases are classified, given as a percentage of the total responses.

We conclude that, in accordance with results of the researches cited, the lunar phases are a phenomenon little understood by most $6^{\text {th }}$ grade pupils, finding that $53.9 \%$ being unable to give any explanation at the beginning of the teaching sequence. Only $11.5 \%$ of pupils presented an explanation related to the angle between the Moon and the Sun in the sky, but they could

\section{Table 3: Categories of mental models of the lunar phases, defined according to the pupils' oral, written and pictorial} explanations at the beginning of the sequence

\begin{tabular}{|c|c|c|}
\hline \multicolumn{3}{|c|}{ Categories of initial mental models of the lunar phases } \\
\hline $\mathrm{M}_{\mathrm{LP}-1}$ & $\begin{array}{l}\text { Models of the angle of incidence of sunlight } \\
\text { The lunar phases are due to the Sun's position with respect to the } \\
\text { Moon }\end{array}$ & \\
\hline & & $\begin{array}{l}\text { "The crescent Moon is because the Sun illuminates from the side, it's } \\
\text { already day and the Sun illuminates the Moon from another position" } \\
\text { "Because the Sun shines on different parts of the Moon" }\end{array}$ \\
\hline \multirow[t]{2}{*}{$\mathrm{M}_{\mathrm{LP}-2}$} & $\begin{array}{l}\text { Eclipse models } \\
\text { The lunar phases are due to the Earth casting a shadow on the Moon }\end{array}$ & \\
\hline & & $\begin{array}{l}\text { "The Earth makes different shadows on the Moon. It depends on where } \\
\text { the Moon is" }\end{array}$ \\
\hline \multirow[t]{2}{*}{$M_{L P-3}$} & Models of Sun's motion & (No drawing) \\
\hline & The Sun changes place and shines differently on the Moon & $\begin{array}{l}\text { "The phases of the Moon change because the Sun moves and shines on } \\
\text { different sides" }\end{array}$ \\
\hline \multirow[t]{2}{*}{$\mathrm{M}_{\mathrm{LP}-4}$} & Models of environmental change & (No drawing) \\
\hline & $\begin{array}{l}\text { The Moon changes shape because of the seasons of the year or } \\
\text { depending on the weather. }\end{array}$ & $\begin{array}{l}\text { "The Moon has phases according to the seasons" } \\
\text { "The New Moon is when the weather is warm, when there is no } \\
\text { beautiful sky and no stars" }\end{array}$ \\
\hline$M_{L P-5}$ & Models of variation in the Moon's position & $\begin{array}{l}\text { The Moon's motion from } 1 \text { day to the next makes it seems to have } \\
\text { different shapes when it is seen from the Earth's surface }\end{array}$ \\
\hline
\end{tabular}


not explain satisfactorily how and why this angle changes.

\section{Group Evolution of Pupils' Explanations}

Table 5 shows examples of group work carried out as a final task in the teaching sequence; these were later discussed as a whole-class activity. In their drawings, the pupils showed the relationship between the Moon's changing position in the sky and the change in its shape as seen from the Earth. Nevertheless, these diagrams lack clarity as to the position of the Sun, the star that illuminates the Moon.

These representations reveal a marked change in conceptual understanding when compared with the beginning of the teaching sequence, when most participants could not offer any explanation as to the cause of the phenomenon, nor describe satisfactorily how the Moon changes shape.

\section{Evolution of Individual Pupils' Ideas}

At the end of the teaching sequence, the children responded again to the initial questionnaire, explaining the lunar phases with a drawing and text. This time a large proportion of participants associated the phenomenon with the Moon's changing position in the sky from 1 day to the next, at the same time of day. Some stated that the phases were due to "how we see the Moon, although half of it is always illuminated." As a consequence, an additional category of models was defined, for later analysis of the teaching sequence development.

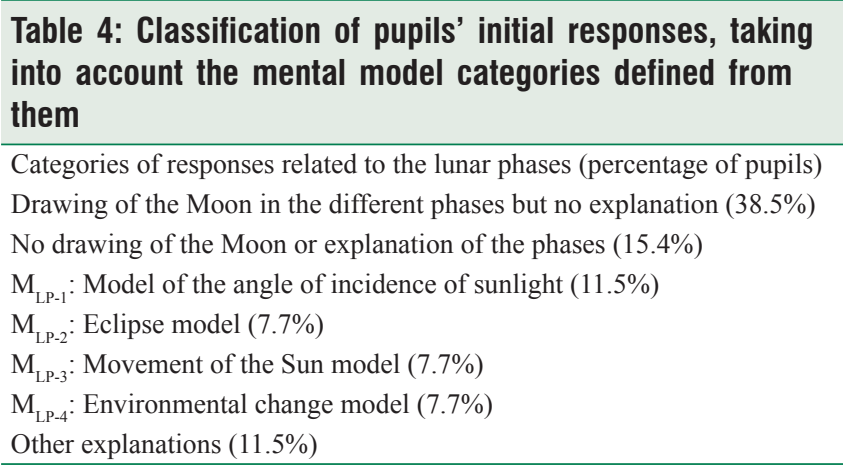

Table 5: Drawings and texts produced during group work, the final task in the teaching sequence explaining the lunar phases

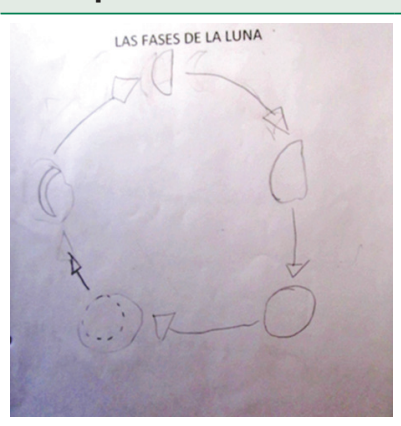

"The Moon moves round and it looks different to us"

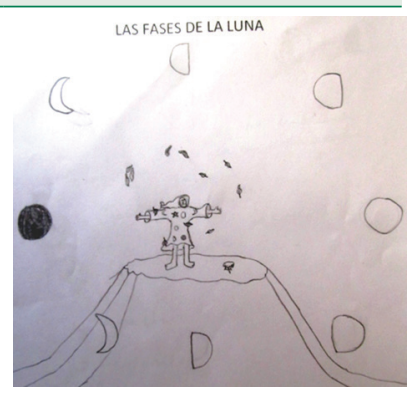

"The Moon moves and that is why it looks different to me"
Comparison of the percentage of pupils assigned to each category at the beginning and the end of the teaching sequence is shown in Figure 4, which includes the proportion of pupils that drew the phenomenon but was not able to explain it, and those who were neither able to draw nor explain it.

The proportion of pupils who were not able to offer any explanation as to the cause of the lunar phases decreased from $53.9 \%$ at the beginning (first two columns of Figure 4) to $23.1 \%$ at the end of the sequence of activities. At the same time, explanations satisfactorily associating the lunar phases with the changing position of the Moon in the sky from 1 day to the next, including category $\mathrm{M}_{\mathrm{LP}-5}$, increased from zero representation at the first activity to over half the pupils on completion of the classes. The inclusion of a considerable proportion of pupils in category $\mathrm{M}_{\mathrm{LP}-5}$ shows the evolution of the mental models of the students, many of whom could not give any explanation for this phenomenon at the beginning of the sequence. Moreover, they did not know about the changing position of the Moon in the sky each day.

In the final activity, $57.8 \%$ of participants were able to associate the illuminated side of the Moon with its corresponding phase, while $46.2 \%$ related the phase to the time of day of the lunar observation. Table 6 presents some pupils' drawings and phrases showing the evolution of their explanations of the lunar phases.

This evolution of ideas about the phenomenon in a significant proportion of students was evident in the final individual interviews, where they could explain the lunar phases from the point of view of the Moon's own motion in the sky and give descriptive and explanatory indications related to the phenomenon:

"[Now in the morning] The Moon is waning and its right side is illuminated." $\left(\mathrm{A}_{2}\right)$

"In the waxing [phases] you see the left side and in the waning the right side. Waxing you see at night, and waning in the morning." $\left(\mathrm{A}_{7}\right)$

"If the Moon is out in the morning its right side is lit up, and the next day it will be smaller... The phases of the

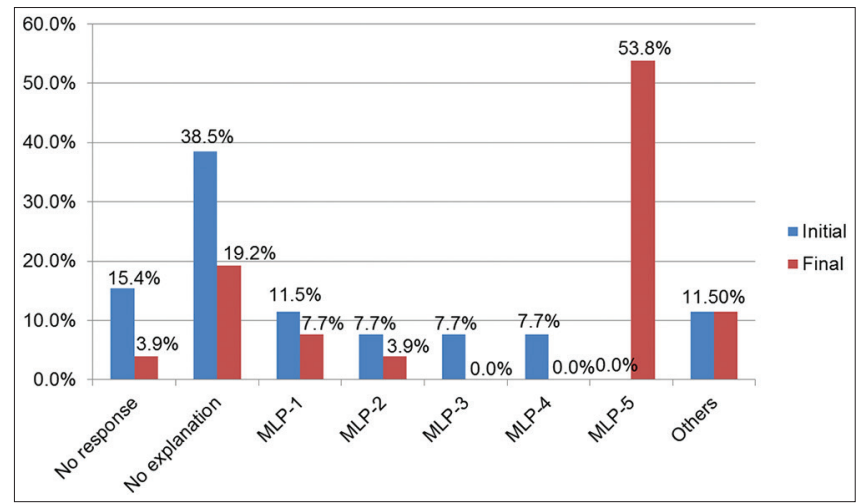

Figure 4: The percentage of pupils whose explanations corresponded to each category of mental models of the lunar phases, at the beginning and the end of the didactic sequence. Included are the pupils who were unable to give any explanation 
Table 6: Evolution of the explanations of some pupils and their classification. Explanatory drawings and texts carried out at the beginning and the end of the teaching sequence

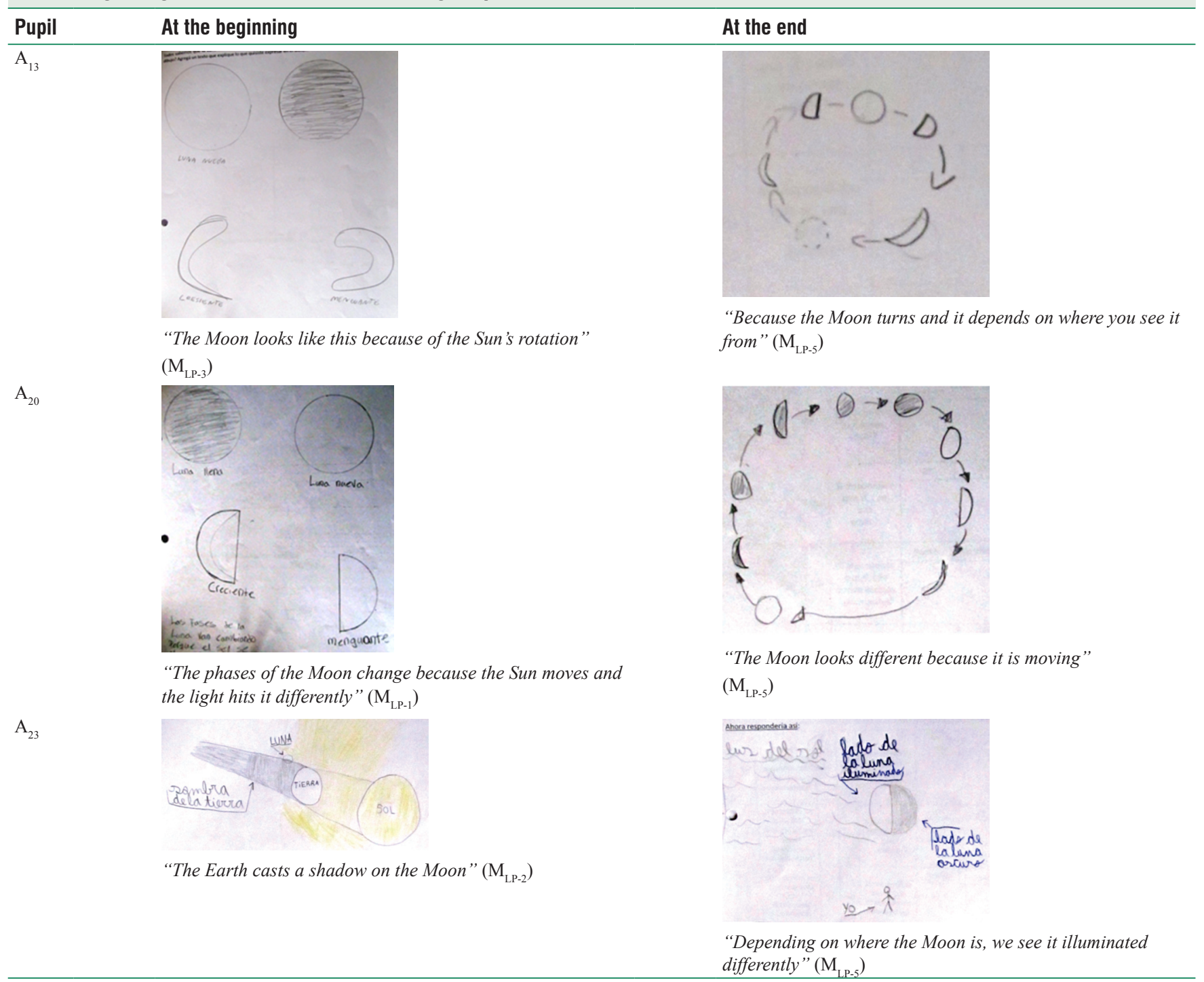

Moon happen because it moves continuously to the east, and because of its closeness [angular] to the Sun." $\left(\mathrm{A}_{10}\right)$ "IIf today the Moon is out at dawn] The Sun lights up its right side and it's waning... The Moon is always halfilluminated, it moves and depending on our point of view, where we're standing, it looks different." $\left(\mathrm{A}_{18}\right)$

"I drew the Sun at one side of the Moon, the Sun is lighting up half of it, and from my point of view I see a quarter of the Moon, that is, I see half of half of it lit up, and depending on the angle I look at it from, I'm going to see a different amount of what is lit up." $\left(\mathrm{A}_{23}\right)$ "When the Moon moves, the side that gets lit up changes. That's why it looks a different shape, although the Moon is always illuminated by half." $\left(\mathrm{A}_{26}\right)$.

It can be seen that a considerable proportion of participants show significant modifications in their explanatory models, even more, if we take into account that at the beginning of the sequence no pupil from the class was able to satisfactorily describe or explain the lunar phases. However, $46.2 \%$ of the children were still not able to explain adequately the phenomenon at the end of the topocentric teaching sequence, which indicates the need for future analysis of the reasons for these difficulties in comprehension.

\section{CONCLUSIONS}

The hypothesis presented in this work is that the difficulties experienced by children and adults in understanding the phenomenon of lunar phases may be due to, among other causes, the use of the heliocentric frame of reference as the only approach to development the subject. For this reason, an alternative teaching proposal was designed and implemented for primary level students, using the topocentric reference frame, associated with direct observation of the sky. The teaching sequence included two innovative diagrams of practical use in describing and explaining 
the lunar phases from the Moon's own motion in the sky. These diagrams, moreover, enable predictions to be made as to the position and shape of our satellite during a complete lunar cycle.

The results found suggest that this focus promotes favorable evolution of the mental models of a large proportion of the students. At the same time, it enables pupils to associate astronomical knowledge with the phenomena they can see every day in the sky. However, a proportion of the students did not make significant progress in their representations of the phenomenon. This may be partly due to the intrinsic complexity of the phenomenon itself, related in part to the need for certain abilities associated with spatial reasoning to understand it.

The comparison between the initial explanations of most of the pupils with those given in the final task of the sequence of activities shows substantial changes in their descriptions and explanations of the phenomenon. Therefore, this alternative focus to traditional approaches, based on the use of the topocentric reference frame, represents a satisfactory didactic resource to improve the teaching of the lunar phases to primary-level children.

The topocentric model presented may be considered an intermediate model (Clement, 2000) in the construction of an object model that places the observer outside the Earth to explain the same phenomenon heliocentrically. Nevertheless, this topocentric model goes beyond being a transition toward more complex models since it has educational value in itself, as it enables students to describe, explain, and predict everyday astronomical phenomena.

\section{REFERENCES}

Aggul Yalcin, M., Yalcin, M. \& Isleyen, T. (2012). Pre-service primary science teachers' understandings of the moon's phases and lunar eclipse. Procedia - Social and Behavioral Sciences, 55, 825-834.

Álvarez, M., Galperin, D. \& Quinteros, C. (2018). Indagación de las concepciones de estudiantes primarios y secundarios sobre los fenómenos astronómicos cotidianos. In: En Papini, M., (Ed.), Las Ciencias de la Naturaleza y la Matemática en el Aula: Nuevos Desafios $y$ Paradigmas. Tandil, Argentina: National University of the Center of the Province of Buenos Aires. p129-142.

Baxter, J. (1989). Children's understanding of familiar astronomical events. International Journal of Science Education, 11(5), 502-513.

Bayraktar, S. (2009). Pre-service primary teachers' ideas about lunar phases. Journal of Turkish Science Education, 6(2), 12-23.

Bisard, W., Aron, R., Francek, M., \& Nelson, B. (1994). Assessing selected physical science and earth science misconceptions of middle school through university preservice teachers. Journal of College Science Teaching, 24, 38-42.

Bryman, A. (2004). Social Research Methods. New York: Oxford University Press.

Callison, P., \& Wright, E. (1993). The effect of teaching strategies using models on pre-service elementary teachers' conceptions about EarthSun-Moon relationships. Annual Meeting of the National Association for Research in Science Teaching, Atlanta, Georgia.

Camino, N. (1995). Ideas previas y cambio conceptual en astronomía. Preconceptions and conceptual change in astronomy. A study with primary school teachers about day and night, seasons and lunar phases.. Enseñanza de las Ciencias, 13(1), 81-96.

Camino, N. (1999). Sobre la didáctica de la astronomía y su inserción en EGB. In: Kaufman, M., \& Fumagalli, L.Y, (Ed.), Enseñar Ciencias Naturales. Buenos Aires, Argentina: Paidós. p143-173.

Clement, J. (2000). Model based learning as a key research area for science education. International Journal of Science Education, 9(22), 1041-1053.
Danaia, L., \& McKinnon, D.H. (2007). Common alternative astronomical conceptions encountered in junior secondary science classes: Why is this so? Astronomy Education Review, 2(6), 32-53.

Dicovskiy, E., Iglesias, M., Karaseur, F., Gangui, A., Cabrera, J., \& Godoy, E. (2012). El problema de la posición del observador y el movimiento tridimensional en la explicación de las fases de la Luna en docentes de primaria en formación. In: Actas de las III Jornadas de Enseñanza e Investigación Educativa en el campo de las Ciencias Exactas y Naturales. La Plata, Argentina: National University of La Plata. p219-230.

Fanetti, T. (2001). The Relationships of Scale Concepts on College Age Students' Misconceptions About the Cause of Lunar Phases. (Master's Thesis, Iowa State University, Ames. Iowa, The United States of America).

Galagovsky, L., \& Adúriz-Bravo, A. (2001). Reference systems in the teaching of Astronomy. An analysis based on a literature review. Enseñanza de las Ciencias, 19(2), 231-242.

Galperin, D. (2011). Propuestas didácticas para la enseñanza de la Astronomía. In: Insaurralde, M., (Ed.), Ciencias Naturales. Líneas de Acción Didáctica y Perspectivas Epistemológicas. Buenos Aires: Novedades Educativas. p189-229.

Galperin, D. (2016). Sistemas de Referencia y Enseñanza de las Ciencias: El Caso de los Fenómenos Astronómicos Cotidianos (Tesis doctoral). Tandil, Argentina: Universidad Nacional del Centro de la Provincia de Buenos Aires, Facultad de Ciencias Exactas. Available from: http://www.ridaa.unicen.edu. $\mathrm{ar} / \mathrm{xmlui} / \mathrm{handle} / 123456789 / 896$. [Last accessed on 2018 Aug 27].

Galperin, D., \& Raviolo, A. (2014). Sistemas de referencia en la enseñanza de la Astronomía. Un análisis a partir de una revisión bibliográfica. Latin American Journal of Physics Education, 8(1), 136-148.

Galperin, D., \& Raviolo, A. (2017). Analysis of images related to day / night, seasons and lunar phases in primary school texts. Revista Electrónica de Investigación en Educación en Ciencias, 12(1), 1-11.

Galperin, D., Prieto, L., \& Heredia, L. (2018). Concepciones de docentes sobre las causas de los fenómenos astronómicos cotidianos. In: Papini, M., (Ed.), Las Ciencias de la Naturaleza y la Matemática en el Aula: Nuevos Desafios y Paradigmas. Tandil: Universidad Nacional del Centro de la Provincia de Buenos Aires. p116-128.

Gilbert, J., \& Boulter, C. (2000). Developing Models in Science Education. Dordrecht, Netherlands: Kluwer Academic Publishers.

Iglesias, M., Dicovskiy, E., Karaseur, F., Cabrera, J., Godoy, E. \& Gangui, A. (2012). La explicación de las fases de la Luna en docentes de primaria en formación: Aportes para la reflexión. In: Memorias del Décimo Primer Simposio de Investigación en Educación en Física. Esquel, Argentina: National University of Patagonia San Juan Bosco. p275-286.

Johnson-Laird, P. (1983). Mental Models. Cambridge: Cambridge University Press.

Lanciano, N. (1989). See and talk like Ptolemy and think like Copernicus. Enseñanza de las Ciencias, 7(2), 173-182.

Lombardi, O. (1998). The notion of model in science. Educación en Ciencias, 2(4), 5-13.

Navarro, P.M. (2009). Aprendizaje y Enseñanza de Astronomía Diurna en Primaria (Tesis doctoral). Alicante, España: University of Alicante.

Palomar, F.R. (2013). Enseñanza y Aprendizaje de la Astronomía en el Bachillerato (Doctoral Thesis, University of Valencia, Valencia, España).

Sadler, P. (1992). The Initial Knowledge State of High School Astronomy Students. (Doctorate Thesis, Harvard University, Cambridge, MA, The United States of America).

Schoon, K. (1992). Students' alternative conceptions of Earth and space. Journal of Geological Education, 40, 209-214.

Sharp, J. (1996). Children's astronomical beliefs: A preliminary study of year 6 children in south-west England. International Journal of Science Education, 18(6), 685-712.

Stahly, L., Krockover, G., \& Shepardson, D. (1999). Third grade students' ideas about the lunar phases. Journal of Research in Science Teaching, 36, 159-177.

Subramaniam, K., \& Padalkar, S. (2009). Visualisation and reasoning in explaining the phases of the moon. International Journal of Science Education, 31(3), 395-417.

Suzuki, M. (2003). Conversations about the moon with prospective teachers in Japan. Science Education, 87(6), 892-910.

Trumper, R. (2001). Assessing students' basic astronomy conceptions from junior high school through university. Australian Science Teachers Journal, 47(1), 21-31. 